\title{
Threats to endangered musk deer (Moschus chrysogaster) in the Khaptad National Park, Nepal
}

\author{
Tilak Thapamagar $^{1}$, Shivish Bhandari ${ }^{1,2^{*}}$, Kishor Ghimire ${ }^{3}$, Daya Ram Bhusal ${ }^{3}$ \\ ${ }^{1}$ Himalayan Biodiversity Network-Nepal, Bharatpur 11, Chitwan, Nepal \\ ${ }^{2}$ Austin Peay State University, Clarksville, Tennessee, USA \\ ${ }^{3}$ Central Department of Zoology, Tribhuvan University, Kirtipur, Kathmandu, Nepal
}

\begin{abstract}
Thapamagar, T., Bhandari, S., Ghimire, K., Bhusal, D.R., 2019. Threats to endangered musk deer (Moschus chrysogaster) in the Khaptad National Park, Nepal. Folia Oecologica, 46: 170-173.

The Alpine musk deer (Moschus chrysogaster) is classified as an "Endangered" species by the IUCN Red list category. We studied anthropogenic pressure on the musk deer population in the Khaptad National Park, Nepal. The questionnaire survey was applied from October to November 2018. Out of 111 respondents, 77\% reported that the primary objective for poacher kills to the musk deer was musk pod, followed by skin $(15 \%)$ and meat (8\%). The major part of the killing tools represented traps; however, $23 \%$ respondents stated that poachers also use snares, $20 \%$ respondents reported guns, and $18 \%$ persons interviewed had no idea regarding the tool the poachers use to kill the musk deer. There was a significant difference between the male and female respondents regarding their opinion on musk deer conservation; male respondents exhibited more positive attitudes towards musk deer conservation than female respondents (Chi-squared 8.21 ; $\mathrm{P}<0.05$ ). People based conservation awareness programs and alternative income generating sources must be employed for long term musk deer conservation in the Nepal Himalayas.
\end{abstract}

\section{Keywords}

conservation, Himalayas, mammals, poachers, Red list

\section{Introduction}

Population trends in the Alpine musk deer (Moschus chrysogaster Hodgson, 1839) reveal a negative population growth to the point that the species has been classified as "Endangered" according to the IUCN Red list (TIMMINS and DucKWORTH, 2008); it is listed in Appendix I of CITES and it is also one of the protected species by the NPWC Act, 1973. The species is endemic to the Himalayan region of Nepal, China, India and Bhutan (GREEN, 1986; Kattel, 1992; Shrestha, 1997). It also acts as an indicator species of the alpine ecosystems at elevations of 2,500 $\mathrm{m}$ asl to 4,500 $\mathrm{m}$ asl (KatTel, 1992; Zhou et al., 2004; Majupuria and Majupuria, 2006). In Nepal, the species is distributed from east to west of the alpine and subalpine regions, including protected and non-protected areas (MAJupuria and Majupuria, 2006; Baral and SHAH, 2008).

The population decline is due to anthropogenic pressures and poaching. The musk deer possesses a valuable musk-secreting gland for which there is high demand in the international market (QURESHI et al., 2013), particularly in the traditional Chinese medicine and the perfume industry (GREEN, 1986). Because of these great values in the international market, poaching substantially threatens the species (ZhixiaO and Helin, 2002; Zhou et al., 2004; THAPAMAGAR et al., 2018). Moreover, degradation and decline in available habitats, resulting from the dependency of the local people on the forest for timber, fodder, food, and medicinal plant (KHAN et al., 2006; MAJUPURIA and MAJUPURIA, 2006; SYed and Ilyas, 2016), increasingly threatens the musk deer throughout most of the Nepal

*Corresponding author:

e-mail: shivish.bhandari@yahoo.com 
Himalayas. The overlapping of grazing areas by livestock creates yet another problem for the musk deer (XIUXIANG et al., 2006). The people in the Himalaya regions are mostly dependent on hotel and restaurant businesses, agriculture, and livestock for their livelihood, which leads to an increase in deforestation and overgrazing of habitats in the musk deer's range (ZHIXIAO and HeLin, 2002). In some geographic areas, the feral dog is becoming a noticeable threat to the species (Thapamagar et al., 2018). Poaching ranks among the most significant threats to the musk deer. Poachers use various leg and neck snares made of nylon rope, to capture and kill individuals of the species (Dendup et al., 2018). Most poaching activities occur in the winter season (DeNDuP et al., 2018). In the winter, musk deer descend near to human settlements, due to the heavy snowfall at higher elevations. At this time, poachers have the greatest chance to trap the animals.

In the Khaptad National Park (KNP) of Nepal, anthropogenic pressure has created noticeable threats to the dwindling wildlife population, including the musk deer. Because of the remoteness and geographical features of this part of the country, there are lacking public awareness programs in respect to wildlife conservation. It is very urgent to study the anthropogenic pressure on musk deer which may show the current scenario of wildlife trafficking around Nepal. In addition, it is important to understand the people perceptions towards the musk deer conservation and their opinions for the sustainable conservation of the species in the Himalayas. In this paper, we studied anthropogenic impacts on the musk deer population in the KNP of Nepal. This study is essential for the sustainable conservation of musk deer in the Himalayan region to safeguard the species for future generations.

\section{Materials and methods}

The study was conducted in the Buffer Zone (Chhanna Khaptad Municipality) of the Khaptad National Park in the Bajhang district of Nepal (Fig. 1). The Khaptad National Park is a very actively visited touristic site due to its attractive scenic views and religious sightseeing. The Park flora comprises 224 species of medicinal herbs, and the meadows are covered with an immense mass of flowering plants in the summer and snow in the winter. The wild boar (Sus scrofa), barking deer (Muntiacus muntjak), Himalayan black bear (Ursus thibetanus), wild dog (Cuonalpinus), and musk deer are examples of major mammalian fauna found in the park (SHRESTHA, 1997; MAJUPURIA and MAJUPURIA, 2006).

We employed an open-type questionnaire survey to understand the threats and people's attitudes toward the musk deer in the KNP in Nepal. Between October and November 2018, we interviewed 111 persons, including the local people (35\%), Buffer Zone User Committee (6\%), park staff (3\%), high school students (19\%) and teachers $(11 \%)$, and farmers $(26 \%)$, regarding the threats and opportunities to the musk deer in KNP.

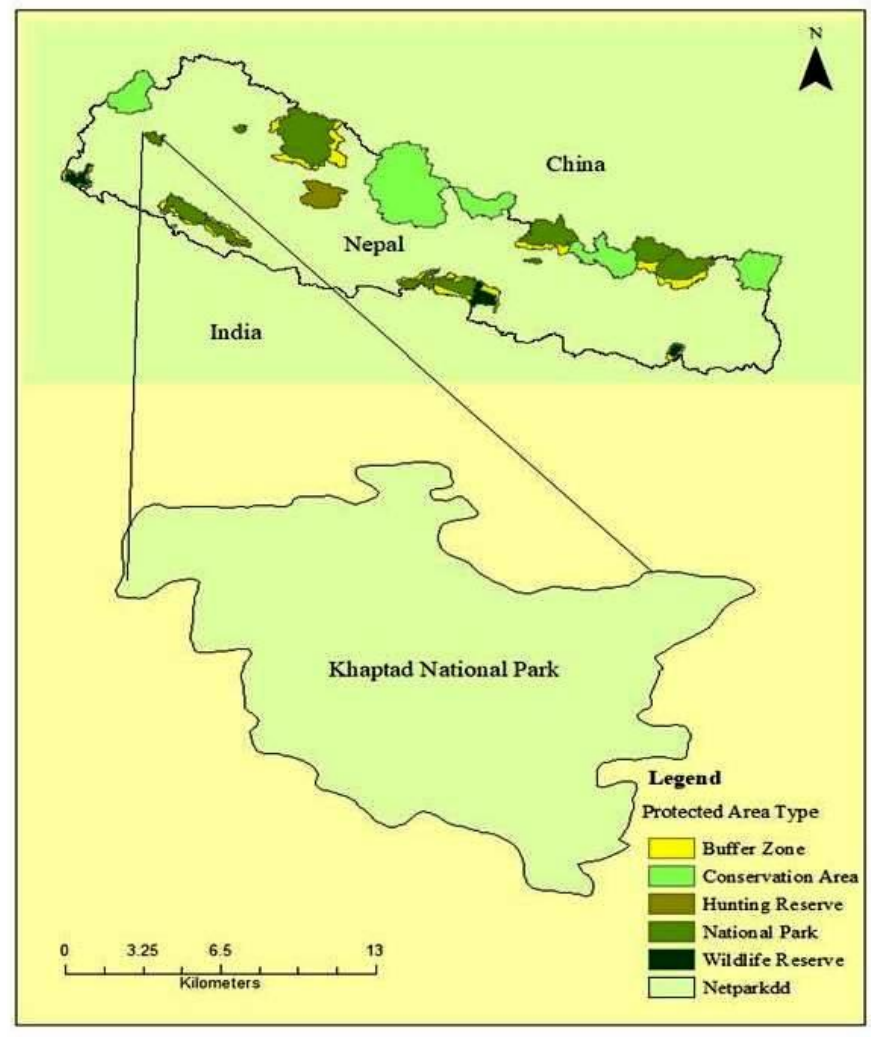

Fig. 1. Study site location, the Khaptad National Park, Nepal. 


\section{Results and discussion}

Our study discovered that musk deer does face anthropogenic pressure in the KNP. In our questionnaire, poachers killed musk deer primarily for the musk pod (77\%) followed by skin $(15 \%)$ and meat $(8 \%)$. Based on the local people's perception, $58 \%$ of respondents stated that poachers killed musk deer seasonally, 19\% stated that poachers killed musk deer monthly, $12 \%$ of respondents declared that poaching activities happened only occasionally, and $11 \%$ of respondents stated that there were weekly poaching activities. The traps were found to be the primary tool used to kill musk deer, followed by snares and guns (Fig. 2).

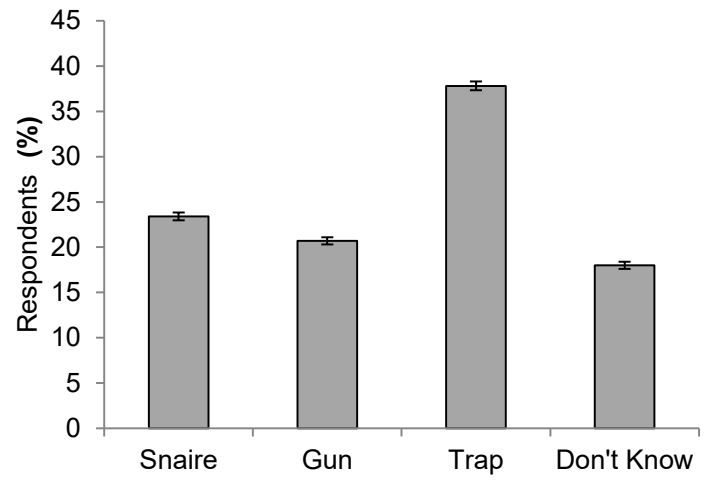

Fig. 2. Peoples' perception towards tools used by poachers to kill musk deer, $(\mathrm{n}=111)$.

Most of the respondents $(83 \% ; \mathrm{n}=111)$ stated that there was a lack of conservation activities regarding musk deer conservation in and around the KNP. Our study demonstrated that $55 \%$ of respondents said that poachers sell musk deer products to the major cities and to the capital (for example, Dhangadhi, Nepalgunj and Kathmandu). $15 \%$ of persons surveyed said that poachers use the local market to sell the musk products; however, $30 \%$ of respondents had no idea regarding where poachers sell musk deer products. The male respondents showed significantly more positive attitudes with respect to musk deer conservation than the female respondents (chi-square statistic $=8.2184, \mathrm{p}<.05)$. Poaching activities were predominantly occurring in the winter season, followed by autumn, spring and summer seasons (Fig. 3). Our survey found no harm, such as crop raiding, to the local people by the musk deer population in the KNP.

The study revealed that the anthropogenic pressure is a serious concern to the musk deer population in the Khaptad National Park. This could be due to the lack of conservation knowledge, poor implementation of policies, unemployment, and low economic status of the local people (BARAL and ShaH, 2008; Bhandari et al., 2015; BHANDARI and BHUSAL, 2017). We found that the conservation awareness program had not been launched in most areas in the park; therefore, this may be a reason that people are unaware of the ecological importance and legal status of the species. Most of the locals depend on agriculture and livestock farming. They shift cowsheds inside the national park during the summer season, which destroys the species habitats. Similarly, firewood collection for cooking is common, which leads to deforestation in most of the areas of the park (SATHYAKUMAR et al., 1993; XiUXIANG et al., 2006; BHANDARI et al., 2015). According to the respondents, the traps and snares were most commonly used as the killing weapons, whereas guns were less utilized. The snares and traps may be less risky to carry and would allow the killing of the animals relatively unnoticed. A similar fact was reported by DENDUP et al. (2018) and THAPAMAGAR et al. (2018) as musk deers were killed by using leg and neck snares. There was a consensus that the poaching activities occurred seasonally, i.e. mostly in the winter season. This result has been supported by DENDUP et al. (2018) studying this issue in the Jigme Dorji National Park, Bhutan and ThaPAMAGAR et al. (2018) in Langtang National Park, Nepal. This may be due to the heavy snow fall to which the musk deer trails are revealed for the poachers to follow. The result is more efficient animal trapping.

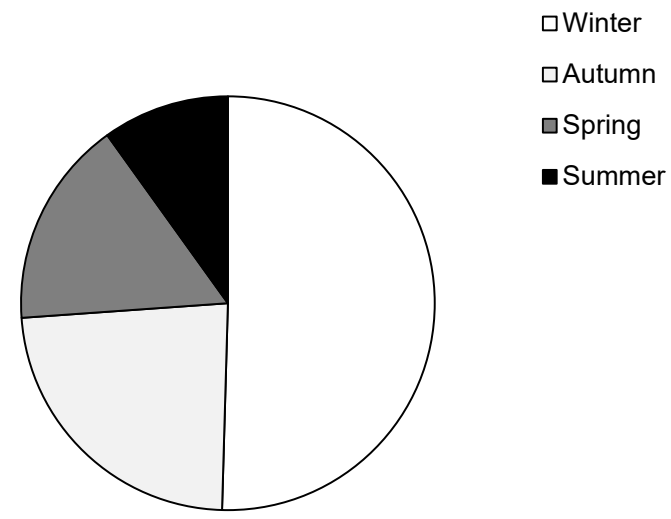

Fig. 3. Poaching of musk deer in different seasons $(n=111)$.

It is very difficult to unveil the market for selling musk pods. All sales are done illegally, so information about the export market is difficult to acquire. Most of the respondents agreed that the market for musk deer was outside the region (i.e. mainly in the city), but some respondents claimed that the meat of the species was sold in the local market. The musk deer conservation is becoming very challenging for the next generations. Therefore, the government of Nepal should strictly implement the laws and policies with zero poaching of musk deer.

\section{Conclusions}

Illegal hunting and poaching are major problems in most parts of Nepal including the KNP. Conservation related programs should be implemented with the goal of raising the musk deer conservation knowledge of the local 
people. If local people become more aware, poaching activities may be reduced at least at the local level. For the sustainable conservation of musk deer, a regular monitoring program should be operated by the government body. In addition, alternative income generating sources, such as ecotourism, should be promoted to increase livelihood income of the local people and to promote wildlife conservation. The proper management of grassland habitats and community forests may reduce the dependency of local people onmusk deer habitats. Stakeholders such as the National park, Buffer Zone Management Committee, and Community Forest Users must play an active role to manage the grassland habitats and forests in proper cooperation with the local people.

\section{Acknowledgements}

We thank the Rufford Foundation UK for providing funding and the Himalayan Biodiversity Network-Nepal for the equipment and field support. We would also like to thank two anonymous reviewers and S. Bojic for editorial feedback. Special thanks go to the park staff, Buffer Zone User Committee, and the local people of the Chhanna Khaptad Municipality of Bajhang District.

\section{References}

Baral, H.S., Shah, K.B., 2008. Wild mammals of Nepal. Kathmandu. Nepal: Himalayan Nature. 188 p.

Bhandari, S., Bhusal, D.R., 2017. Notes on human-hyena (Hyaena hyaena Linnaeus, 1758) conflict in Jajarkot, Kalikot and Mahottari districts of Nepal. Journal of Institute of Science and Technology, 22:127-131.

Bhandari, S., Rijal, B., Khanal, S., 2015. Status survey of striped hyena (Hyaena hyaena Linnaeus, 1758) and their conservation approaches in Rautahat and Sarlahi forests, Nepal. Journal of Natural History Museum, 29: 49-59.

Dendup, P., Namgay., Lham, C., 2018. Winter distribution and poaching of Himalayan musk deer Moschus chrysogaster and Moschus leucogaster in Jigme Dorji National Park, Bhutan. International Journal of Conservation Science, 9: 193-198.

GreEN, M.J., 1986. The distribution, status and conservation of the Himalayan musk deer Moschus chrysogaster. Biological Conservation, 35: 347-375.
KATTEL, B., 1992. Ecology of Himalayan musk deer in Sagarmatha National Park, Nepal. PhD thesis. Colorado State University, USA. 76 p.

Khan, A. A., QuReshi, B.U.D., Awan, M.S., 2006. Impact of musk trade on the decline in Himalayan musk deer Moschus chrysogaster population in Neelum valley, Pakistan. Current Science, 91: 696-699.

MAJUPURIA, T.K, MAJUPURIA, R.K., 2006. Wildlife and protected areas of Nepal. Bangkok, Thailand: Craftsman Press Ltd. 549 p.

Qureshi, B.D., Anwar, M., Hussain, I., Beg, M.A., 2013. Habitat utilization of Himalayan musk deer (Moschus chrysogaster) in the Musk Deer National Park Guraiz, Azad Jammu and Kashmir, Pakistan. The Journal of Animal and Plant Sciences, 23: 1366-1369.

Sathyakumar, S., Prasad, S.N., Walker, S., 1993. Status of captive Himalayan forest Himalayan musk deer Moschus chrysogaster in India. International Zoo Yearbook, 32: 32-38.

Shrestha, T.K., 1997. Mammals of Nepal, with reference to those of India, Bangladesh, Bhutan and Pakistan. Hingham, United Kingdom: Steven Simpson Natural History Books. 371 p.

Syed, Z., ILYAS, O., 2016. Habitat preference and feeding ecology of alpine Himalayan musk deer (Moschus chrysogaster) in Kedarnath Wildlife Sanctuary, Uttarakhand, India. Animal Production Science, 56: 978-987.

Thapamagar, T., Magar, K.T., Pandey, M., Bhandari, S., Bhusal. D.R., 2018. Habitat preferences and conservation status of Himalayan musk deer (Moschus chrysogaster) in Langtang National Park, Nepal. Journal of Ecology \& Natural Resources, 2(6): 000152.

Timmins, R.J., Duckworth, J.W., 2008. Moschus leucogaster. The IUCN Red List of Threatened Species 2008: e.T13901A4363664. [cit. 2019-10-12].

Xiuxiang, M., Caiquan, Z., Jinchu, H., CaO, L., Zhibin, M., Jinchao, F., Yisun, Z., Yinjiu, Z., 2006. Musk deer farming in China. Animal Science, 82: 1-6.

Zhixiao, L., Helin, S., 2002. Effect of habitat fragmentation and isolation on the population of alpine Himalayan musk deer. Russian Journal of Ecology, 33: 121-124.

Zhou, Y., Meng, X., Feng, J., Yang, Q., Feng, Z., XIA, L., BARTOS, L., 2004. Review of the distribution, status and conservation of musk deer in China. Folia ZoologicaPraha, 53: 129-140.

Received June 26, 2019 Accepted October 16, 2019 